\title{
Relationship Management Amidst OEM Demands for Supplier Price Cuts: A Cross-Industry Study
}

\author{
R. Mohan Pisharodi, John W. Henke Jr., and Ravi Parameswaran
}

\begin{abstract}
Original equipment manufacturers (OEMs) often seek price cuts from their suppliers through an adversarial approach. At the same time, other OEMs have adopted a cooperative approach based on the belief that adversarial tactics will damage the possibility of good supplier-OEM working relationship. While price cuts can obviously improve OEM profitability in certain situations, researchers have also recognized the competitive advantages that can be gained through cooperation with suppliers. This research seeks to find out whether supplier-OEM relationships are adversely affected by OEM demand for price cuts. It seeks to find out whether demands for price concessions can coexist with good supplier-OEM relationships. A research model incorporating relationship constructs as well as a construct representing price pressure and another representing overall relations between the OEM and its supplier is tested using data collected from suppliers in three different industries. Structural equation modeling and analysis lead to the conclusion that price pressure can coexist with good relationships as long as OEMs and their suppliers take the managerial actions required for the maintenance of good working relationships. The general pattern of relationships among the research constructs was found to be substantially similar in the three industries, although cross-industry differences were observed.
\end{abstract}

R.M. Pisharodi $(\bowtie) \bullet J . W$. Henke Jr. • R. Parameswaran

Oakland University, Rochester, MI, USA

e-mail: pisharod@oakland.edu; henke@oakland.edu; paramesw@oakland.edu 